\title{
GAS TURBINE CO-FIRING OF STEELWORKS AMMONIA WITH COKE OVEN GAS OR METHANE: A FUNDAMENTAL AND CYCLE ANALYSIS
}

\author{
S. G. Hewlett ${ }^{\star}$, A. Valera-Medina, D. G. Pugh, P. J. Bowen \\ Cardiff University School of Engineering, \\ Cardiff, Wales, UK, CF24 3AA. \\ Email: hewlettsg4@cardiff.ac.uk, valeramedinaa1@cardiff.ac.uk
}

\section{ABSTRACT}

Following on from successful experimental trials employing ammonia/hydrogen blends in a model gas turbine combustor, with favorable $\mathrm{NO}_{\mathrm{x}}$ and unburned fuel emissions, a detailed numerical study has been undertaken to assess the viability of using steelworks by-product ammonia in gas turbines. Every metric ton (tonne) of steel manufactured using a blast furnace results in approximately $1.5 \mathrm{~kg}$ of by-product ammonia, usually present in a vapor form, from the cleansing of coke oven gas (COG). This study numerically investigates the potential to utilize this by-product for power generation. Ammonia combustion presents some major challenges, including poor reactivity and a propensity for excessive $\mathrm{NO}_{\mathrm{x}}$ emissions. Ammonia combustion has been shown to be greatly enhanced through the addition of support fuels, hydrogen and methane (both major components of COG). CHEMKIN-PRO is employed to demonstrate the optimal ratio of ammonia vapor, and alternatively anhydrous ammonia recovered from the vapor, to COG or methane at equivalence ratios between 1.0 and 1.4 under an elevated inlet temperature of 550K. Aspen Plus was used to design a Brayton-Rankine cycle with integrated recuperation, and overall cycle efficiencies were calculated for a range of favorable equivalence ratios, identified from the combustion models. The results have been used to specify a series of emissions experiments in a model gas turbine combustor.

Keywords: ammonia, power, steelworks, gas turbine

\section{INTRODUCTION}

In 2017, world crude steel production was 1,691 million tonnes (Mt), around $75 \%$ of which was produced using the blast furnace to basic oxygen furnace (BF-BOF) route [1]. In a modern blast furnace, 450 to $480 \mathrm{~kg}$ of coke is required as a reductant for every tonne of pig iron manufactured using this route [2, 3]. During the pyrolysis of coal into coke, a gaseous fraction of moisture and volatiles is evolved. This fraction, termed raw coke oven gas (COG), is laden with contaminants with the potential to foul and corrode pipework. These contaminants include tar, ammonia $\left(\mathrm{NH}_{3}\right)$ and hydrogen sulfide $\left(\mathrm{H}_{2} \mathrm{~S}\right)$ amongst others. Cleaned, COG has a volumetric composition of approximately $61 \%$ hydrogen $\left(\mathrm{H}_{2}\right), 24 \%$ methane $\left(\mathrm{CH}_{4}\right), 7 \%$ carbon-monoxide (CO) and small percentages of nitrogen $\left(\mathrm{N}_{2}\right)$, carbon-dioxide $\left(\mathrm{CO}_{2}\right)$, ethane $\left(\mathrm{C}_{2} \mathrm{H}_{6}\right)$ and ethene $\left(\mathrm{C}_{2} \mathrm{H}_{4}\right)$. COG has a typical higher heating value (HHV) of 17.0 to $18.0 \mathrm{MJ} / \mathrm{Nm}^{3}$ [4-6] and is used around the plant for the provision of heat and power. For each tonne of coke produced, around $3 \mathrm{~kg}$ of by-product ammonia is removed from the raw COG [4]. Therefore, as a conservative estimate, $1.7 \mathrm{Mt}$ of by-product ammonia was produced globally in the steel industry in 2017. Likewise, ammonia by-product is also present in the waste streams of many other industries including oil refining, dairy farming and biomass processing.

Ammonia is gaining increased research interest as a green hydrogen (i.e. renewably produced hydrogen) carrying energy vector $[7,8]$ and a carbon-free fuel. Ammonia manufactured from green hydrogen is termed green ammonia.

Having a vapor pressure of $\sim 1 \mathrm{MPa}$ at atmospheric temperature, ammonia is easily stored as a liquid [7]. In comparison with other liquid fuels, it has a gross calorific value of $22.5 \mathrm{MJ} / \mathrm{kg}$, similar to that of methanol and half that of diesel. 
With a 2017 global trade of $150 \mathrm{Mt}$ (nitrogen equivalent) [9], there exists significant transportation and storage infrastructure.

While ammonia can be recovered directly from the COG stream, the more conventionally employed technique is the indirect water-wash process, where water is used to strip contaminants from the gas stream and is then itself stripped of these contaminants in a separate circuit. After tar removal, the sour water, an aqueous mix containing $\mathrm{NH}_{3}, \mathrm{H}_{2} \mathrm{~S}$, hydrogen cyanide $(\mathrm{HCN})$ and $\mathrm{CO}_{2}$, can be treated in a variety of ways as presented in Figure 1.

In many process arrangements, the sour water is concentrated to an ammonia vapor. This vapor may be catalytically decomposed, incinerated, recovered as anhydrous ammonia or reacted with sulfuric acid to produce fertilizer (i.e. ammonium sulfate). The production of fertilizer is not favored in Europe due to its lack of suitability for local soils [10].

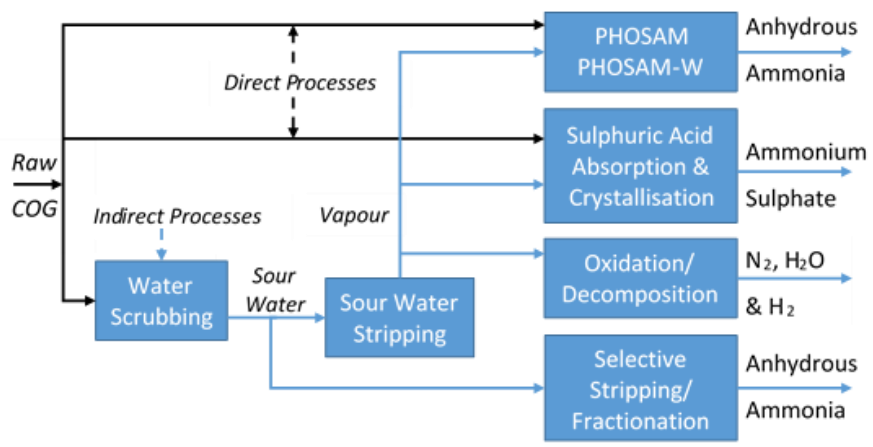

Figure 1. BY-PRODUCT AMMONIA FROM COG - PROCESSING ROUTES [11]

Although there are in practice many examples of energy recovery from the decomposition and incineration of by-product ammonia [5, 12], energy recovery does not appear to be a requirement. Even with the benefit of energy recovery, poorly managed ammonia combustion is a significant issue as it has the potential to produce high levels of $\mathrm{NO}_{\mathrm{x}}$, raising health and environmental concerns [13].

This paper examines numerically the potential offered by steelworks by-product ammonia, in both its ammonia vapor (AV) and recovered anhydrous ammonia (AA) forms, to produce power using gas turbine (GT) technology. The priority is to minimize $\mathrm{NO}_{\mathrm{x}}$ concentrations and other harmful emissions, whilst optimizing operational performance.

\section{RATIONALE}

According to the Worldsteel Association, the steel industry generates between 7 and $9 \%$ of direct global $\mathrm{CO}_{2}$ emissions [14], making the industry a significant contributor of anthropogenic carbon-dioxide to the planet's atmosphere. By 2050, global steel production is expected to increase by 1.5 times that of 2017 levels [1]. Meanwhile, the International Energy Agency (IEA) has stated that between 2016 and 2030, the energy intensity of crude steel production needs to decline by $1.2 \%$ annually to meet the IEA's sustainable development targets [15].
Ammonia, a carbon free fuel, has the potential to lower carbon emissions in the steel industry. Present in a waste stream of integrated steelworks, it is a free energy resource.

Unfortunately, ammonia has poor combustion characteristics, including slow burning velocity, narrow flammability limit, high auto-ignition temperature and the aforementioned propensity for high $\mathrm{NO}_{\mathrm{x}}$ emissions.

In 1967, Verkampf et al. [16] found the addition of $28 \%$ hydrogen to ammonia (simulating partial and controlled cracking) resulted in some burning characteristics approximating those of conventional gaseous fuels, potentially enabling their use in existing infrastructure. Since then several studies have investigated the addition of support fuels, namely hydrogen or methane, as a method to increase ammonia's reactivity and consequently its performance in GT technology [17-19]. Recent experimental studies undertaken by Cardiff University's Gas Turbine Research Centre (GTRC) demonstrated the potential to employ lean premixed $\mathrm{NH}_{3} / \mathrm{H}_{2}$ mixtures in a staged model GT combustor, with $\mathrm{NO}_{\mathrm{x}}$ and unburned fuel concentrations $<50 \mathrm{ppm}$ [20].

COG, as a potential support fuel for by-product ammonia combustion, has three main strengths. First, it is composed of approximately $60 \%$ hydrogen $\left(\mathrm{H}_{2}\right)$, which has been shown to aid ammonia's low reactivity. Secondly, even in the case of a steel plant importing some of its coke [21], levels of COG production can exceed its utilization, resulting in flaring (for safety) [21, 22]. This freely available fuel could instead be used to support ammonia combustion. Thirdly, coking plants do not only exist in integrated steelworks where a variety of support fuels may be available. As by-product ammonia is a derivative of COG cleansing, COG will necessarily be available on-site as a potential support fuel for by-product ammonia resulting from the coking process.

Methane, as a surrogate for natural gas, was also investigated for its potential as a support fuel, being readily available on integrated steelworks sites. Natural gas usage represents around 5\% of energy use on integrated facility sites in the steel industry [1]. If a proportion of the energy derived from natural gas can be provided for through the utilization of ammonia by-product instead, this could serve to lower carbon emissions in those processes currently using natural gas alone.

Hence, both COG and methane were considered as potential support fuels for by-product ammonia in both its AA and $\mathrm{AV}$ forms.

\section{INITIAL INVESTIGATIONS OF FUEL MIXES}

The compositions of both AV and COG are variable. COG composition varies with coke oven feedstock composition and the processing conditions of time and temperature. AV composition is primarily dependent on the temperature and pressure under which the vapor is concentrated, due to the differing partial pressures of the component gases. AV composition also varies with the degree to which the acid gases are removed upstream. This study assumes a plant arrangement as presented in Figure 1, where the majority of the sulfur is stripped from the sour water prior to vapor concentration. 
Representative compositions for $\mathrm{COG}$ and $\mathrm{AV}$ were derived from literature and industry and are specified in Figures 2 and 3 . These compositions were then used in the subsequent analyses.

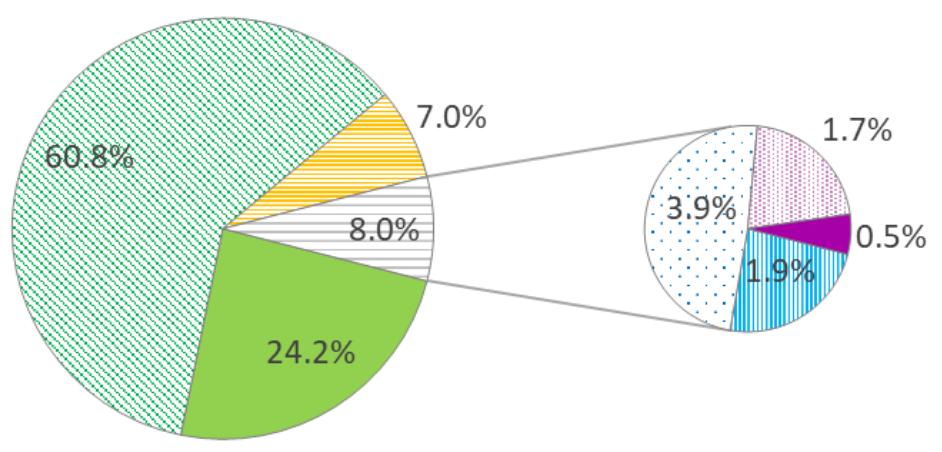

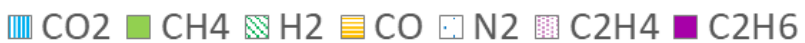

Figure 2. REPRESENTATIVE COG COMPOSITION VOL-\% [5, 6, 22].

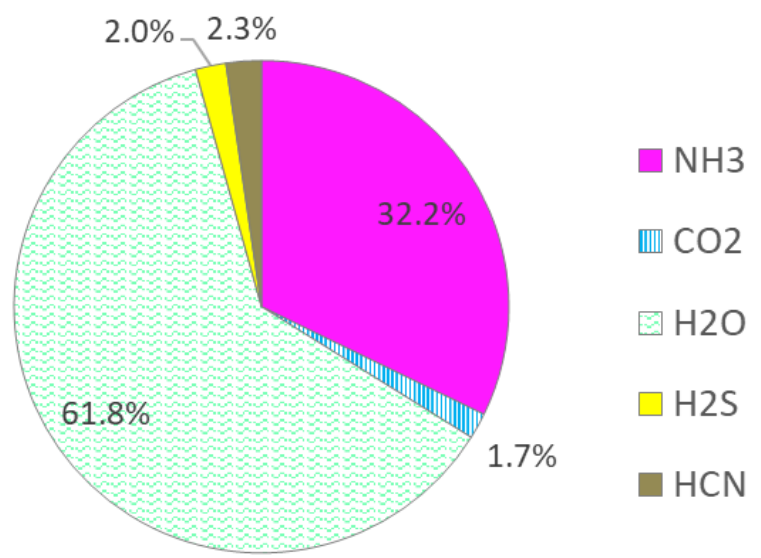

Figure 3. REPRESENTATIVE AMMONIA VAPOR COMPOSITION VOL-\% $[5,10]$

The representative AV and COG have HHVs of 8.0 and $45.8 \mathrm{MJ} / \mathrm{kg}\left(6.2\right.$ and $\left.18.3 \mathrm{MJ} / \mathrm{Nm}^{3}\right)$ respectively.

Two fuel mix matrices were generated. The first matrix blended AV with each of the support fuels - COG or methane in turn. The second matrix mixed AA in a similar fashion. The proportion of $\mathrm{AV}$ or $\mathrm{AA}$ to support fuel was varied in 5\% increments. For example, mix 1 contained 5\% $\mathrm{CH}_{4}$ to $95 \%$ $\mathrm{AV} / \mathrm{AA}$, mix $210 \% \mathrm{CH}_{4}$ to $90 \% \mathrm{AV} / \mathrm{AA}$ and so on.

\section{Equilibrium Modeling}

The complex kinetics of $\mathrm{NO}_{\mathrm{x}}$ formation with fuel-bound nitrogen are significant, often resulting in super equilibrium levels of production [13]. However, using chemical 0-D equilibrium-based analysis, employing a qualitative approach, indicated which proportions of ammonia versus support fuel give mixes with comparatively lower pollutant concentrations; hence identifying the most promising mixes for experimental investigation.
Each test matrix contained 38 mixes, plus the pure AA or AV fuel. Air-fuel equivalence ratios $(\Phi)$ from 0.75 to 1.4 , at 0.05 increments were simulated. With such a large number of cases (i.e. 546 per matrix), equilibrium investigation offered an opportunity to indicate, with minimal processing resources, the mixes offering the lowest potential $\mathrm{NO}_{\mathrm{x}}$ and $\mathrm{CO}$ products. GASEQ, the 0-D equilibrium program used, calculates the products of a reaction through the minimizing of Gibbs free energy for multiple reacting species of gas [23].

Valera-Medina et al. [24] stabilized a flame with a $61 \%$ $\mathrm{NH}_{3}$ to $39 \% \mathrm{CH}_{4}$ blend. Lower percentages of $\mathrm{CH}_{4}$ were either impossible to ignite or too unstable to maintain practically. Increase in equivalence ratio and surprisingly pressure, were found to lower $\mathrm{NO}_{\mathrm{x}}$ levels. However, under rich, low $\mathrm{NO}_{\mathrm{x}}$ conditions, $\mathrm{CO}$ levels were found to be unacceptably high. This study has therefore sought to increase the reactivity of the mixes, to offset the need for greater levels of carbon containing support fuel, by providing a preheated inlet temperature of $550 \mathrm{~K}$, achievable in subsequent experimental programs. Ambient pressure was set to $1 \mathrm{~atm}(0.1 \mathrm{MPa})$.

\section{Equilibrium Results}

All cases were ranked from lowest to highest $\mathrm{NO}_{\mathrm{x}}$ concentration (comprising $\mathrm{NO}$ and $\mathrm{NO}_{2}$ ). Having emphasized the inherent limitations of equilibrium modeling, the selection of the best cases nonetheless necessitates a threshold value. Therefore, a concentration limit of $97 \mathrm{ppmV}$ for $\mathrm{NO}_{\mathrm{x}}$ (calculated from $200 \mathrm{mg} / \mathrm{Nm}^{3}$ ) was taken as the threshold. The figure of 200 $\mathrm{mg} / \mathrm{Nm}^{3}\left(\mathrm{NO}_{2}\right.$ equivalent) is the legislated European Union (EU) limit for medium combustion plants (MCPs) using GT technology (over 70\% loading) for gaseous fuels other than natural gas. This limit will be reduced from $200 \mathrm{mg} / \mathrm{Nm}^{3}$ to 75 $\mathrm{mg} / \mathrm{Nm}^{3}$ in December 2018 [25]. However, considering this legislation does not apply to post-combustion plants designed to purify the waste gases from industrial processes by combustion (not operated as independent combustion plants) or to coke battery furnaces, it is unclear how GT technology using byproduct ammonia and COG would be legislated for. This approach therefore seems reasonable at this stage, especially given the $\mathrm{NO}_{\mathrm{x}}$ reduction capability offered by selective noncatalytic reduction and selective catalytic reduction technologies at $30-75 \%$ and $60-85 \%$ respectively [26].

$\mathrm{NO}_{\mathrm{x}}$ concentrations in this paper have been normalized to dry at $15 \% \mathrm{O}_{2}$ (in keeping with GT technology), as stipulated in the EU regulations. $\mathrm{CO}$ and $\mathrm{NH}_{3}$ product concentrations are also calculated as dry.

Cases below the stated $\mathrm{NO}_{\mathrm{x}}$ threshold were ranked for $\mathrm{CO}$ concentration. A maximum concentration of $1 \%$ (10000 ppmV) $\mathrm{CO}$ enabled selection of six $\mathrm{AV}$ and five $\mathrm{AA}$ mixes. $\mathrm{CO}$ is monitored, but not legislated for in the MCP regulations. Although this $\mathrm{CO}$ seems very high, in practice, secondary air and further reactions would greatly reduce these values. $\mathrm{The}_{\mathrm{NO}}$ and $\mathrm{CO}$ concentrations for these mixes are plotted in Figures 4 to 7 .

The results for equilibrium emissions indicate that the lower the proportion of support fuel, the lower the values of $\mathrm{NO}_{\mathrm{x}}$ and $\mathrm{CO}$. Also the greater the $\Phi$, the lower the levels of $\mathrm{NO}_{\mathrm{x}}$, but 
the higher the levels of $\mathrm{CO}$, as expected. Although all qualifying cases were for $\Phi>1, \mathrm{AV}$ cases are shown for all simulated values of $\Phi$, to demonstrate the contrast in product concentrations between lean and rich conditions (see Figures 4 and 5).

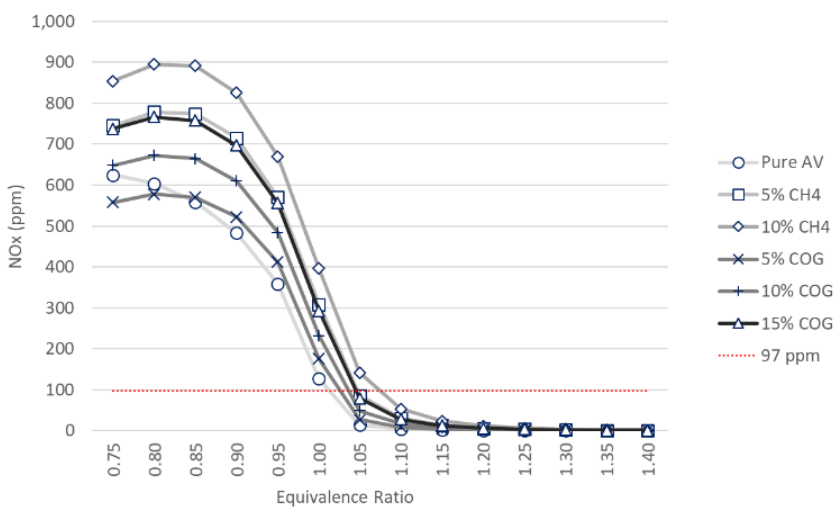

Figure 4. $\mathrm{NO}_{\times}$CONCENTRATIONS BY $\Phi$ FOR AV MIXES AT EQUILIBRIUM (550K INLET, 1 ATM)

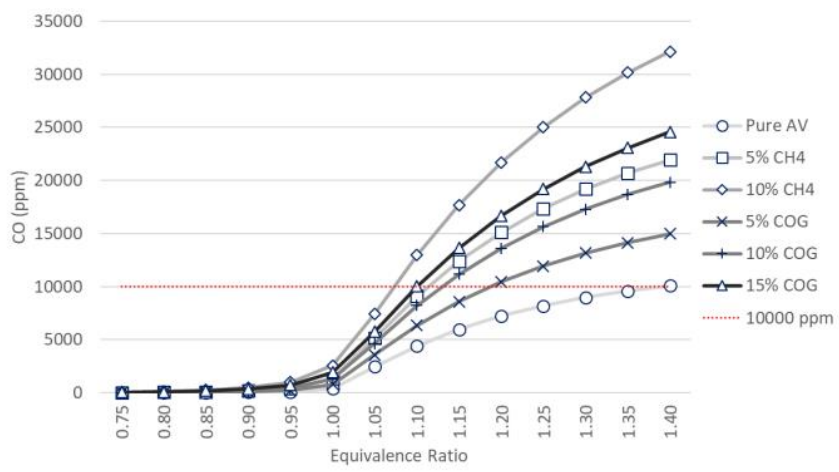

Figure 5. CO CONCENTRATIONS BY $\Phi$ FOR AV MIXES AT EQUILIBRIUM (550K INLET, 1 ATM)

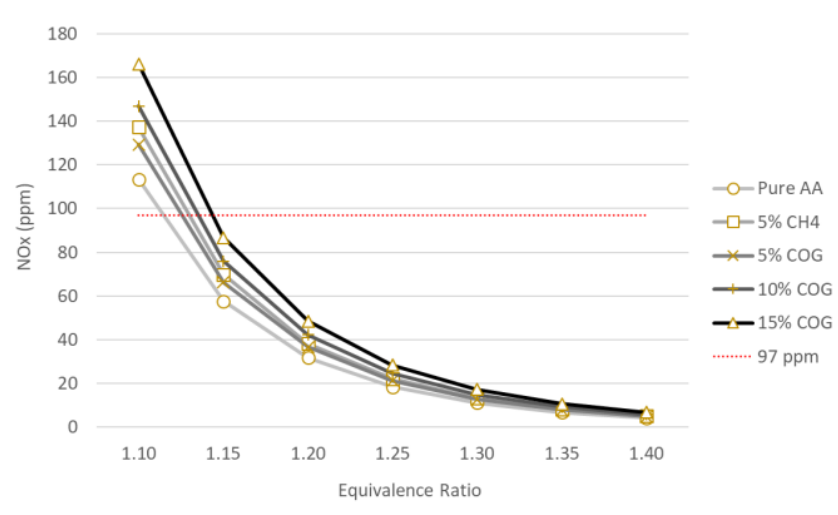

Figure 6. $\mathrm{NO}_{\times}$CONCENTRATIONS BY $\Phi$ FOR AA MIXES AT EQUILIBRIUM (550K INLET, 1 ATM)

Figure 8 shows the adiabatic flame temperatures for the AA and $\mathrm{AV}$ mixes between $\Phi=1.0$ and $\Phi=1.4$. At $\Phi=1.0$ the temperature of each AV mix was between $234 \mathrm{~K}$ and $364 \mathrm{~K}$ lower than for its respective AA mix, dependent on mix. The difference in temperature between equivalent $\mathrm{AA}$ and $\mathrm{AV}$ mixes increased slightly as $\Phi$ increased. Temperature varied more for $\mathrm{AV}$ mixes than for AA mixes due to the significant and varying water fraction, lowering the flame temperature. At $\Phi=1.0$, the temperature for any given mix was around $220 \mathrm{~K}$ and $250 \mathrm{~K}$ higher than for the same mix at $\Phi=1.4$ (for $\mathrm{AA}$ and $\mathrm{AV}$ mixes respectively).

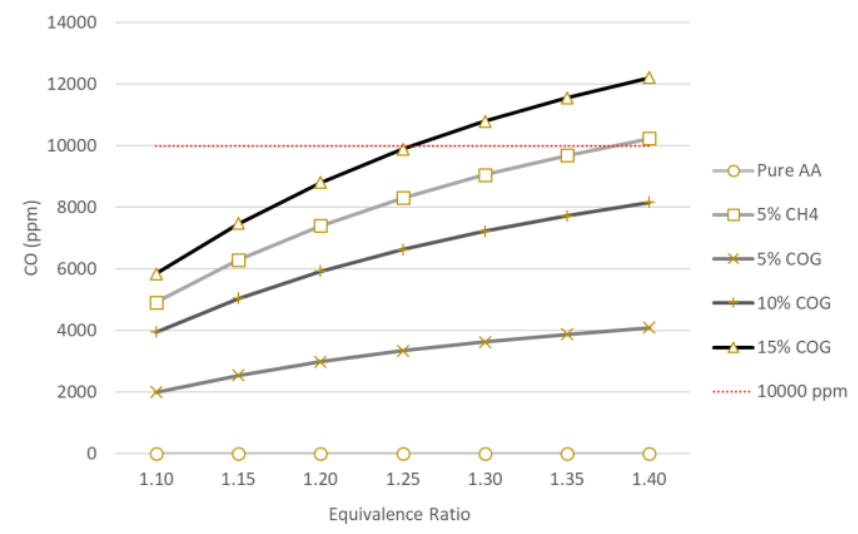

Figure 7. CO CONCENTRATIONS BY $\Phi$ FOR AA MIXES AT EQUILIBRIUM (550K INLET, 1 ATM)

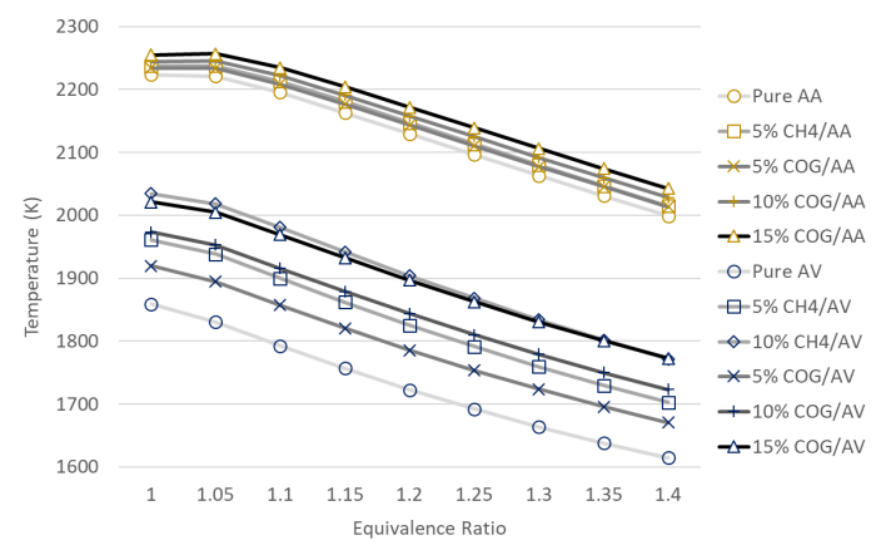

Figure 8. ADIABATIC FLAME TEMPERATURE BY $\Phi$ FOR AAAND AV MIXES AT EQUILIBRIUM (550K INLET, 1 ATM)

Higher temperature promotes the dissociation of atmospheric nitrogen, increasing $\mathrm{NO}_{\mathrm{x}}$ via the Zeldovich mechanism. Gibbs free energy equations likewise resolve to suggest the $\mathrm{NO}_{\mathrm{x}}$ concentrations for the $\mathrm{AV}$ mixes reach below 97 ppm at $\Phi$ values 0.1 lower than for the equivalent AA mixes (i.e. $\Phi 1.05$ instead of 1.15).

To its detriment, $\mathrm{AV}$ has higher $\mathrm{CO}$ than $\mathrm{AA}$ for equivalent mixes. For $5 \% \mathrm{CH}_{4}$ for example, the $\mathrm{AV}$ mix breaches $\mathrm{CO}$ of $10000 \mathrm{ppm}$ at $\Phi$ just above 1.1 compared with $\Phi$ between 1.35 and 1.4 for AA. This is because the carbon content in AV/COG mixes comes not only from the $\mathrm{COG}$, as is the case for AA/COG mixes, but also from the contribution of the $\mathrm{HCN}$ and $\mathrm{CO}_{2}$ components in $\mathrm{AV}$, making the carbon content of $\mathrm{AV}$ mixes considerably higher than for equivalent AA mixes. 
Figure 9 illustrates this differing carbon content for equivalent $\mathrm{AA}$ and $\mathrm{AV}$ mixes using $15 \% \mathrm{COG}$ with $85 \% \mathrm{AA}$ or $85 \% \mathrm{AV}$. The $\mathrm{AV}$ mix has around $63 \%$ more carbon than its equivalent AA mix.

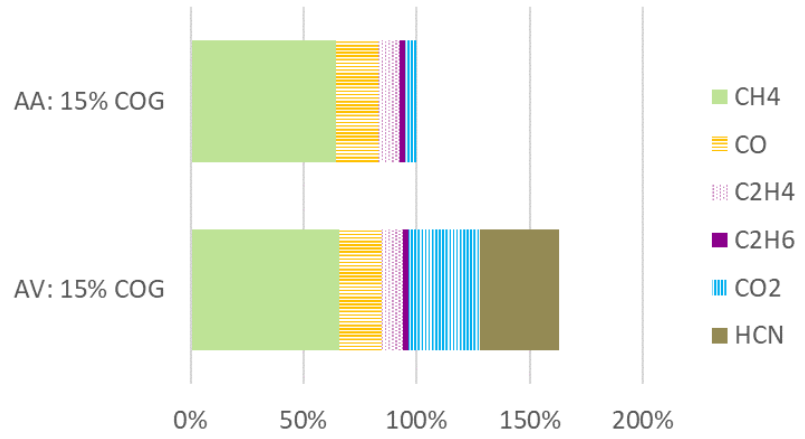

Figure 9. RELATIVE CARBON CONTENT OF $85 \%$ AA or AV TO $15 \%$ COG MIXES

In summary, the equilibrium modeling suggests the optimal balance of $\mathrm{NO}_{\mathrm{x}}$ versus $\mathrm{CO}$ product is centered between $\Phi 1.05$ to 1.1 for $\mathrm{AV}$ mixes and 1.15 to 1.25 for AA mixes.

\section{KINETICS INVESTIGATION - FLAME SPEED}

The PREMIX reactor in CHEMKIN-PRO was employed to provide 1-D simulations of changes in laminar flame speed, as markers of comparable flame reactivity. Solutions were based on an adaptive grid of 1000 points, with multi-component transport properties and trace species approximation.

The eleven mixes were investigated for their flame speed at inlet temperature $550 \mathrm{~K}$ and a pressure of $0.1 \mathrm{MPa}$. The chemical mechanisms used in these simulations were those developed by Tian et al. [27] and Okafor et al. [18].

In numerical studies of several mechanisms by Hua et al. $[28,29]$ Tian's mechanism, developed to simulate $\mathrm{CH}_{4}-\mathrm{NH}_{3}$ combustion, was found to be the most representative for predicting $\mathrm{NO}_{\mathrm{x}}$ emissions using rich equivalence ratios of 1.03 to 1.26. Okafor et al. developed and validated a $\mathrm{CH}_{4}-\mathrm{NH}_{3}$ mechanism, seeking to improve on a measured under-prediction in flame speed by Tian's mechanism. This was achieved by incorporating some reactions from Tian's mechanism into the prevailing mechanism for methane reactions, namely the GRI Mech 3.0 (which lacks some important ammonia oxidation steps). The two mechanisms used will henceforth be referred to as the Tian mech and the Okafor mech, or ' $\mathrm{T}$ ' and ' $\mathrm{O}$ ' respectively in the plots.

The AV composition was normalized without the presence of $\mathrm{H}_{2} \mathrm{~S}$ as the mechanisms do not include sulfur chemistry.

\section{Flame Speed - Results and Discussion}

Figures 10 and 11 show the simulated flame speeds for the $\mathrm{AV}$ and $\mathrm{AA}$ mixes respectively. Pure AV gave no results.

There is good agreement between the two mechanisms for AV mix flame speeds, especially at values of $\Phi$ where the equilibrium investigation predicted the most favorable product profiles were likely to occur (i.e. 1.05 to 1.1 ).
There is less agreement in the flame speed predictions between the mechanisms for the AA cases. In contrast to the under prediction of flame speed by the Tian mech, found by Okafor $e t a l$., the Tian mech is predicting a faster flame speed than the Okafor mech.

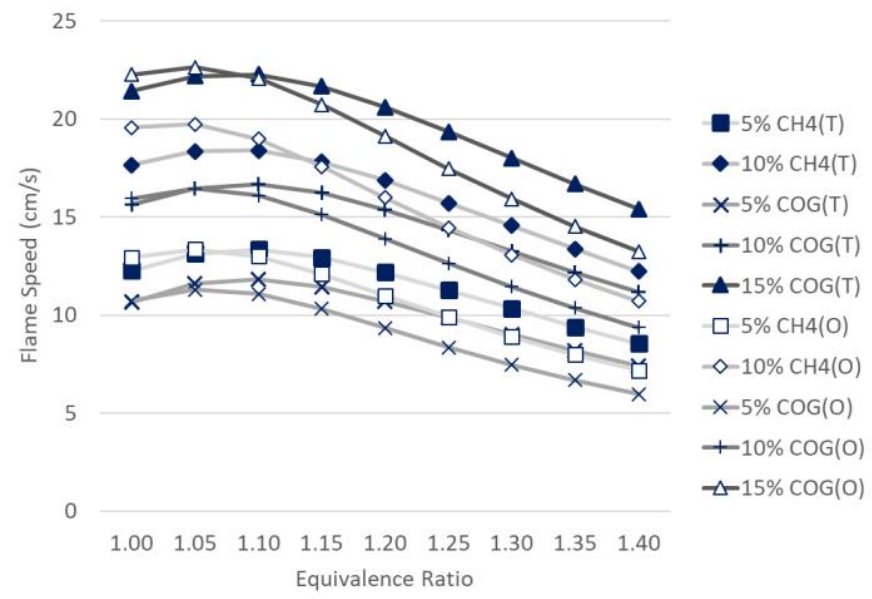

Figure 10. FLAME SPEED BY Ф FOR AV MIXES (550K, $0.1 \mathrm{MPa})$

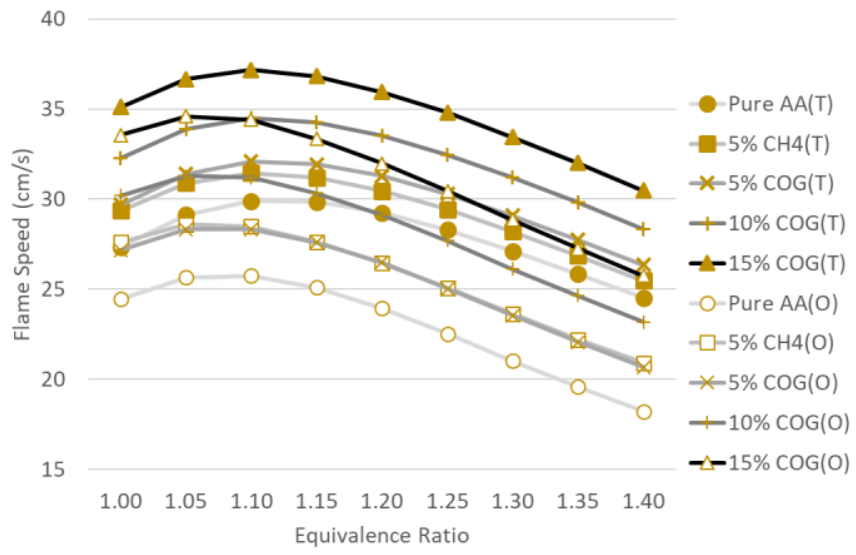

Figure 11. FLAME SPEED BY Ф FOR AA MIXES (550K, 0.1 MPa)

As Kumar and Meyer found during their work on ammoniahydrogen flames, the Tian mech can both significantly over predict and under predict flame speed depending on the consideration of heat losses and the degree of energy content coming from the ammonia. They suggest that when using the Tian mech, predictions were more accurate where $80 \%$ of the energy content is provided by ammonia compared to 20 and $50 \%$ and when ignoring heat losses [30]. The selected mixes derive energy content from ammonia in the region of $80 \%$ or more and heat losses are not considered, which may explain the apparent reversal in the predictions of Okafor et al.

Flame speeds for equivalent $\mathrm{AV}$ and AA mixes (i.e. 15\% COG) are compared with that of methane as a surrogate for natural gas in Figure 12. The methane is simulated under the same preheated conditions, employing the GRI-Mech 3.0 reaction mechanism. It can be seen that for $15 \% \mathrm{COG}$ with AA, 
laminar flame speed predictions for the previously stated $\Phi$ values of interest (with solid data points) are similar to those of lean $\mathrm{CH}_{4}$, at values of $\Phi$ typically employed in natural gas GTs (i.e. 0.5 to 0.6) [31]. At these $\Phi$, methane flame speeds range from 29.3 to $49.4 \mathrm{~cm} / \mathrm{s}$. Three of the five AA mixes and none of the AV mixes sit within this range. This suggests some equivalency in the reactivity of three of the selected mixtures and that stable flames should be achievable under these conditions. Of the AV mixes, $15 \%$ COG has the greatest predicted speed of $22-23 \mathrm{~cm} / \mathrm{s}$. Reduction of the water fraction during the vapor concentration process could lift these speeds to the desired range.

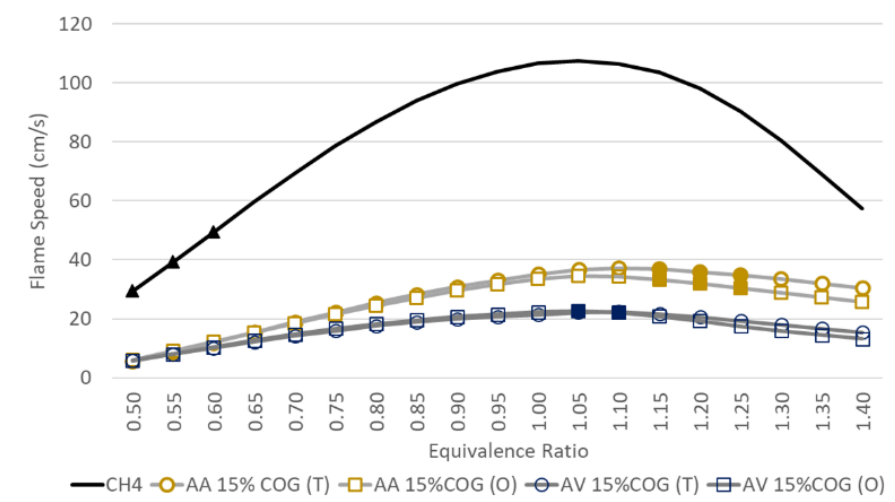

Figure 12. FLAME SPEED BY $\Phi$ FOR AV/AA 15\% COG MIXES VS METHANE (550K, $0.1 \mathrm{MPa})$

\section{KINETICS INVESTIGATION - REACTOR NETWORK}

Using CHEMKIN-PRO and the same two reaction mechanisms, the selected mixes were modeled for their behavior in a hybrid PSR-PFR network, commonly used to simulate GT mixing and flow characteristics $[32,33]$. Consisting of a single feed of premixed air and fuel, the arrangement, shown schematically in Figure 13, has been shown to model representative emission concentrations from an $\mathrm{NH}_{3} / \mathrm{H}_{2}$ premixed swirling flame at Cardiff University's GTRC [20]. This is the same rig proposed for the subsequent $\mathrm{NH}_{3} / \mathrm{CH}_{4} / \mathrm{COG}$ experimental studies.

The preheated fuel and air is fed into a first cluster (C1) of three perfectly stirred reactors PSR1 to PSR3, representing the mixing zone at the inlet, the central recirculation zone (CRZ) and the flame zone respectively.

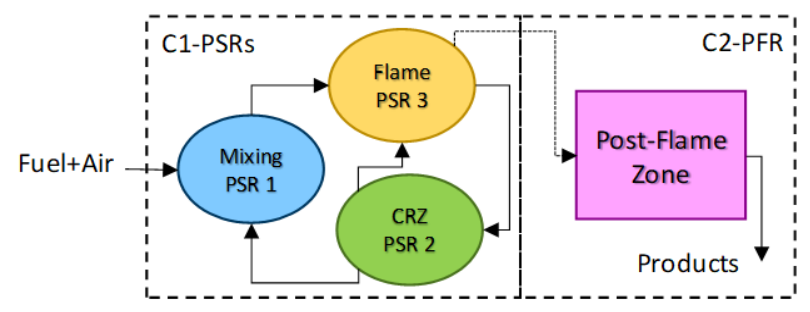

Figure 13. REACTOR NETWORK - SCHEMATIC

The second cluster (C2) is a $40 \mathrm{~cm}$ plug flow reactor (PFR), representing the post flame zone. Recirculation and residence times were as in the previous $\mathrm{NH}_{3} / \mathrm{H}_{2}$ study [19]. Inlet conditions were $550 \mathrm{~K}$ and $1 \mathrm{~atm}(0.1 \mathrm{MPa})$, for $\Phi$ of 1.0 to 1.4 with 0.05 increments.

\section{Reactor Network - Results and Discussion}

Both mechanisms were in close agreement for adiabatic flame temperature for all cases, with a maximum difference between mechanisms of $14 \mathrm{~K}$ for $\mathrm{AV}$ cases and $10 \mathrm{~K}$ for AA cases. Predictions for $\mathrm{CO}$ product were also very closely matched between mechanisms for all cases.

As relevant values for heat losses are to be derived from experimental data in a subsequent study, they have not been included in this model. Consequently, temperatures reached in reality are likely to be significantly lower than those modeled.

\section{AV Cases}

For two mixes, namely pure and 5\% COG with AV, both mechanisms predicted the chemistry of the mixes as incapable of reacting under the specified conditions. Therefore, these two mechanisms were discounted from further investigation. For all other $\mathrm{AV}$ mixes, the Okafor mech consistently predicted a failure to react for $\Phi$ of 0.05 less than that predicted by the Tian mech, as shown in Figure 14.

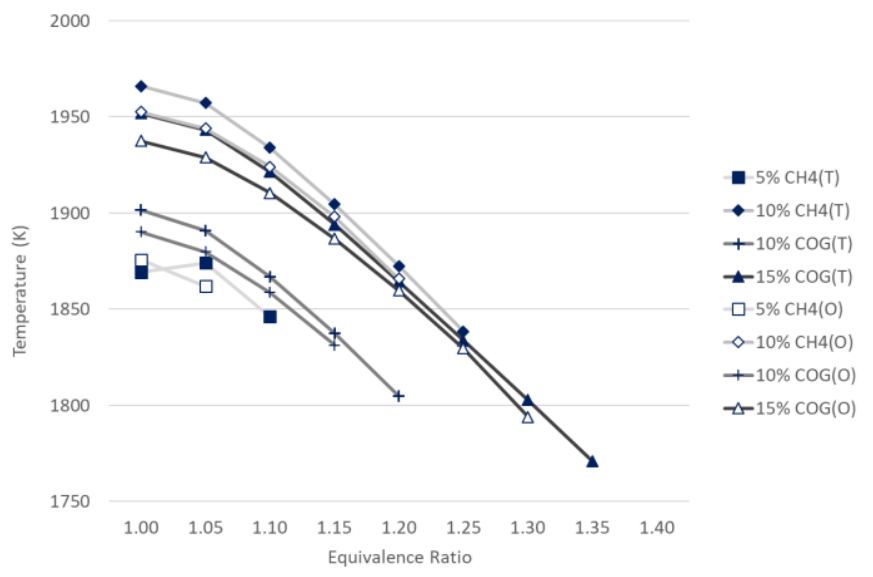

Figure 14. TEMPERATURE BY $\Phi$ FOR AV MIXES - REACTOR NETWORK (550K INLET, $0.1 \mathrm{MPa}$ )

The $5 \% \mathrm{CH}_{4}$ case failed for $\Phi>1.05$ and 1.1 (for the Okafor and Tian mechs respectively). This poor reactivity, coupled with the general trend of higher $\mathrm{NO}_{\mathrm{x}}$ at low $\Phi$, favors the other mixes.

The simulations are conducted under atmospheric pressure (0.1 MPa) conditions. This is to allow for the comparison of modeled data with that to be subsequently obtained from an experimental rig operating at, and moderately above, atmospheric pressure. However, in practice, industrial GTs commonly operate at pressures well above $1 \mathrm{MPa}$.

Increasing the pressure has the potential to greatly lower $\mathrm{NO}_{\mathrm{x}}$, so can address the issue of high $\mathrm{NO}_{\mathrm{x}}$ [20]. This is discussed in more detail in the summary of this section. Additionally, if heat losses were factored in, high temperature $\mathrm{NO}_{\mathrm{x}}$ formation via the Zeldovich mechanism would be less than predicted. The predicted $\mathrm{NO}_{\mathrm{x}}$ and $\mathrm{CO}$ products for the $\mathrm{AV}$ mixes are plotted in Figures 15 and 16 respectively. 
The $10 \%$ COG mix has the advantage of lower $\mathrm{NO}_{\mathrm{x}}$ and $\mathrm{CO}$ than the $15 \%$ COG mix, due in part to the lower flame temperatures resulting from the higher water content and also due to the influence of $\mathrm{H}_{2} \mathrm{O}$ in kinetically reducing $\mathrm{NO}_{\mathrm{x}}$ formation [20]. However, both mechanisms predict significantly lower reactivity for the $10 \% \mathrm{COG}$ mix, with failure to react at $\Phi$ $=0.15$ less than for $15 \%$ COG.

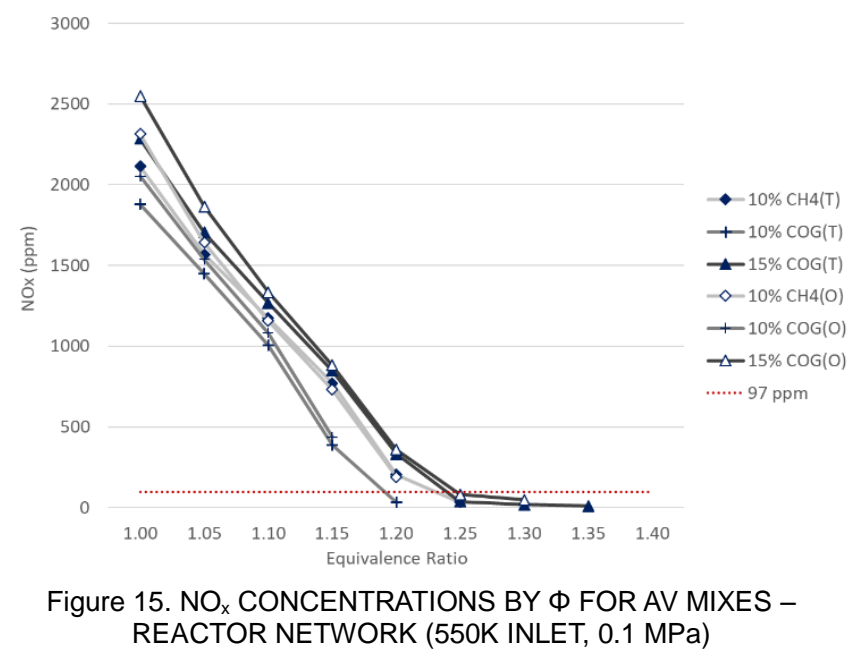

Figure 16 shows how, at $\Phi=1.1$ for example, $\mathrm{CO}$ for $10 \%$ $\mathrm{CH}_{4}$ is 30 to $60 \%$ higher than for $15 \%$ and $10 \%$ COG, favoring these over the $10 \% \mathrm{CH}_{4}$ mix.

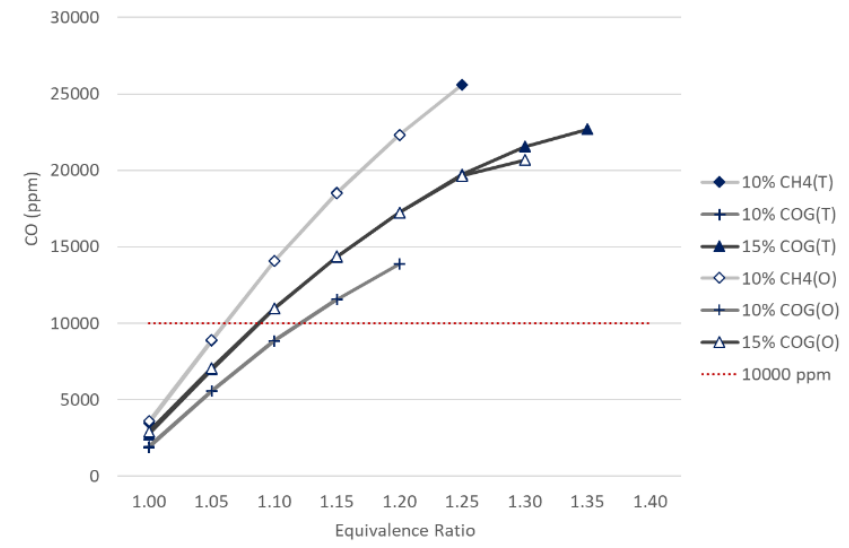

Figure 16. CO CONCENTRATIONS BY $\Phi$ FOR AV MIXES - GT NETWORK (550K INLET, 0.1 MPa)

Considering the potential benefits of high pressures for lowering $\mathrm{NO}_{\mathrm{x}}$, the $15 \%$ COG mix's main disadvantage is that it breaches 10000 ppm CO before $\Phi=1.1$, around 0.05 less than for the $10 \%$ COG mix.

The CO product of the $15 \%$ COG mix could be greatly reduced through the removal of $\mathrm{HCN}$ and $\mathrm{CO}_{2}$ from the $\mathrm{AV}$. This is because, as previously shown in Figure 9, these two components represent $63 \%$ of the mix's carbon content. This removal could be achieved through the exploitation of their differing partial pressures.
Ammonia slip (i.e. unreacted ammonia in the products) was not predicted to be a problem at $\Phi \leq 1.15$ for either case, with lower ammonia product values for $15 \% \mathrm{COG}$.

Considering the potential for pollutant reductions, superior reactivity and faster flame speed, $15 \% \mathrm{COG}$ is the most attractive AV mix.

\section{AA Cases}

As previously stated, both mechanisms were in close agreement for temperature. There was a maximum difference of $42 \mathrm{~K}$ between mixes (at $\Phi=1.4$ ). Across the range of $\Phi$, the peak temperature for each mix was approximately $180 \mathrm{~K}$ higher than the lowest temperature, as shown in Figure 17. All mixes gave results for all values of $\Phi$.

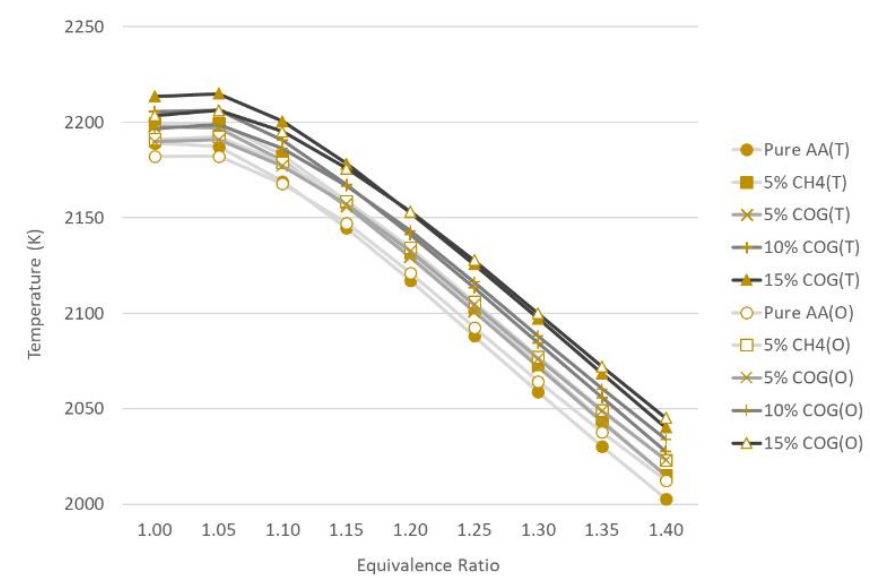

Figure 17. TEMPERATURE BY $\Phi$ FOR ALL AA CASES - GT NETWORK (550K INLET, $0.1 \mathrm{MPa})$

Figure 18 shows $\mathrm{NO}_{\mathrm{x}}$ levels for all mixes at $\Phi>1.1$ and $\Phi$ $<1.3$, where variability was greatest, with the Tian mech predicting levels almost twice the level of the Okafor mech for pure AA at $\Phi=1.2$ (i.e. $191 \mathrm{vs} 111 \mathrm{ppm}$ ). Apart from the results for pure AA using the Okafor mech, the variability in $\mathrm{NO}_{\mathrm{x}}$ levels between mixes is modest (e.g. $329 \pm 27$ ppm for $\Phi=1.15$ ).

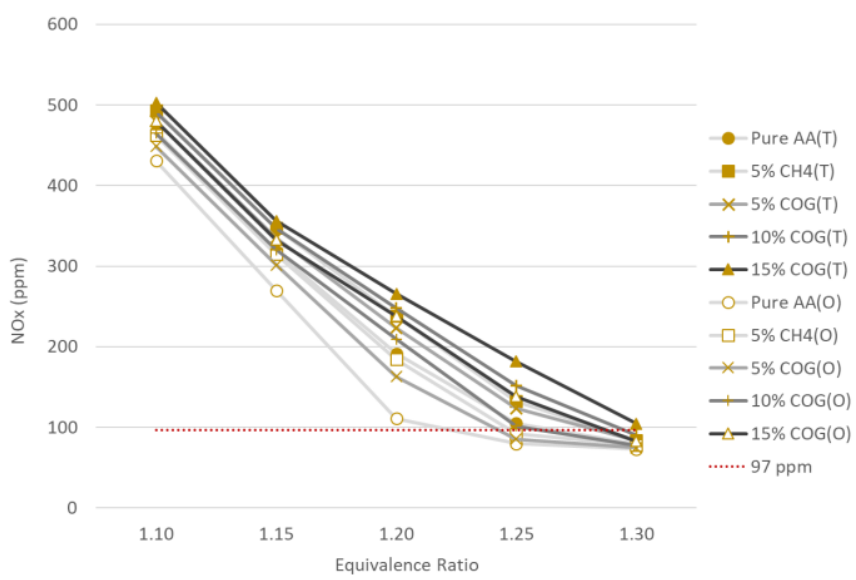

Figure 18. $\mathrm{NO}_{x} \mathrm{BY} \Phi$ FOR ALL AA CASES - GT NETWORK (550K INLET, $0.1 \mathrm{MPa}$ ) 
Ammonia, in various forms, is used in $\mathrm{NO}_{\mathrm{x}}$ reduction $\left(\mathrm{DeNO}_{\mathrm{x}}\right)$ technologies whereby $\mathrm{NH}_{3}$ reacts with $\mathrm{NO}$ to produce $\mathrm{N}_{2}$ and water. For ammonia based fuels, as $\Phi$ increases, two things occur: the level of unburnt $\mathrm{NH}_{3}$ in the products increases and the $\mathrm{NO}_{\mathrm{x}}$ concentration decreases, limiting the consumption of $\mathrm{NH}_{3}$ in reactions with NO. Therefore, a small increase in $\Phi$ can lead to a sudden and rapid increase of $\mathrm{NH}_{3}$ product.

As shown in Figure 19, the two mechanisms are in close agreement for $\mathrm{NH}_{3}$ product where $\Phi \leq 1.3$. Concentrations of $\mathrm{NH}_{3}$ product between mixes are also very similar for values of $\Phi$ $\leq 1.3$. However, at $\Phi>1.3$ the mechanisms do not agree concerning the $\Phi$ at which excessive ammonia slip would occur. The Okafor mech predicts excessive ammonia slip in all cases apart from $15 \%$ COG for the given range of $\Phi$, whereas the Tian mech has no cases of excessive slip. The $<7 \mathrm{ppm}$ (up to 5 $\mathrm{mg} / \mathrm{Nm}^{3}$ ) limit for $\mathrm{NH}_{3}$ in the products reflects best available techniques for ammonia slip associated with DeNOx processes [4].

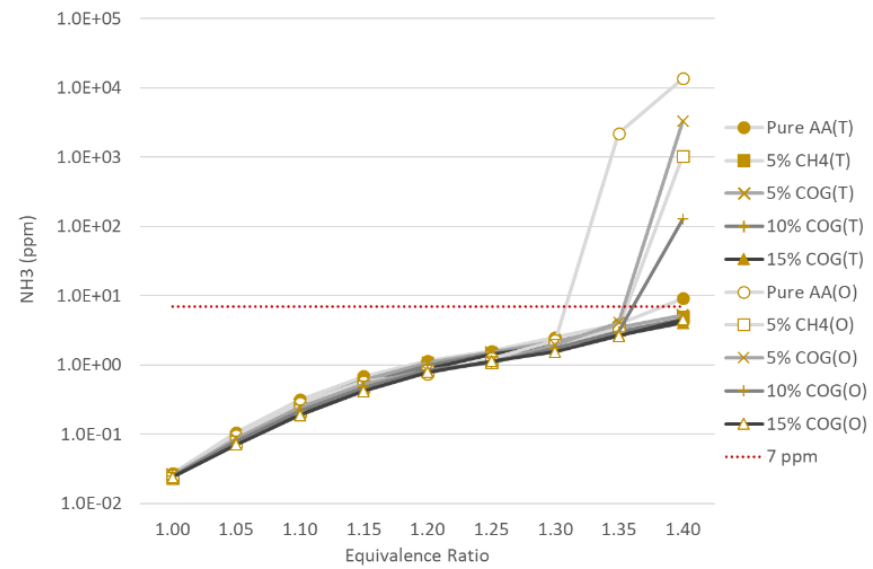

Figure 19. $\mathrm{NH}_{3}$ BY Ф FOR ALL AA CASES - GT NETWORK (550K INLET, $0.1 \mathrm{MPa}$ )

The mixes with lower reactivity are more prone to ammonia slip. The inclusion of heat losses is likely to exacerbate ammonia slip issues, as lower temperatures result in lower reactivity.

CO levels are $<10000 \mathrm{ppm}$ for all AA cases at $\Phi \leq 1.25$. Considering this and the limited variation in $\mathrm{NO}_{\mathrm{x}}$ product between mixes it is possible to maximize for temperature and reactivity by choosing the $15 \%$ COG mix for use at $\Phi \leq 1.25$. This mix is also the optimum mix for flame speed and is best placed to limit the likelihood of ammonia slip once heat losses (and hence lower reactivity) are considered.

\section{Summary of Kinetics Results}

Although $\mathrm{NO}_{\mathrm{x}}$ predictions are higher for $\mathrm{AV}$ than for equivalent $\mathrm{AA}$ mixes at 1 atm, $\mathrm{NO}_{\mathrm{x}}$ has been shown to reduce with increasing pressure. The results for AV and AA with $15 \%$ COG, over a range of pressures below that of typical GT operating conditions, are plotted in Figure 20, using the Tian mech.

The model predicts considerable improvements with moderate pressure increases and suggests that at 8 atm and above, an AV mix would have lower $\mathrm{NO}_{\mathrm{x}}$ product than the equivalent AA mix, as was the case in the equilibrium modeling.

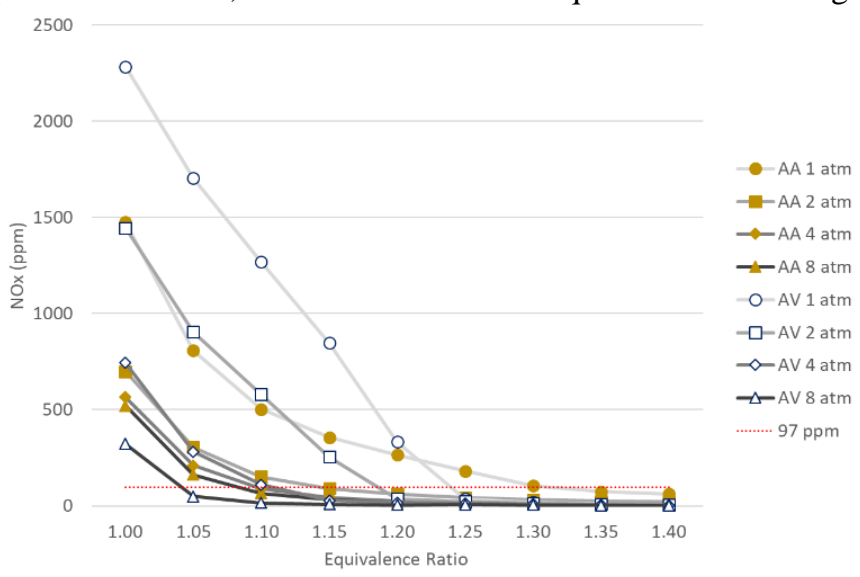

Figure 20. NO $\mathrm{BY}$ Ф FOR 15\% COG WITH AA or AV UNDER INCREASING PRESSURES (550K INLET) - TIAN MECH

This may be due to the water content reducing flame temperature and the action of $\mathrm{H}_{2} \mathrm{O}$ in kinetically reducing $\mathrm{NO}$ formation as described in the humidified $\mathrm{NH}_{3} / \mathrm{H}_{2}$ study.

At 8 atm, $\mathrm{NO}_{\mathrm{x}}<97 \mathrm{ppm}$ for the AV mix at $\Phi<1.05$ and for the AA mix at $\Phi<1.1$. Therefore, with the higher pressures typical of GT technology these values of $\Phi$ should be acceptable as lower limits. For $15 \%$ COG with AV or AA, CO breaches $10000 \mathrm{ppm}$ at $\Phi<1.1$ and $>1.25$ respectively. This suggests an operating $\Phi$ of between 1.05 and 1.1 to be suitable for the AV mix and between 1.1 and 1.25 suitable for the AA mix.

The potential also exists to employ staged combustion, burning richer in a primary zone to reduce $\mathrm{NO}_{\mathrm{x}}$, and employing secondary air to consume unburned fuel. This has been demonstrated to be effective for $\mathrm{NH}_{3}$ mixtures experimentally [20], but has not been included as part of this numerical study. Staged combustor experiments will be included as part of the subsequent experimental program.

Given their superior performances in the GT network and flame speed simulations, $15 \%$ COG with AV (HHV of 11.1 $\mathrm{MJ} / \mathrm{kg}$ ) and $15 \% \mathrm{COG}$ with AA (HHV of $24.6 \mathrm{MJ} / \mathrm{kg}$ ) were selected as the best mixes for each type, on which to base the Aspen Plus simulations and future experimental studies.

\section{CYCLE INVESTIGATION USING ASPEN PLUS}

To gauge an approximate power output from the $15 \% \mathrm{COG}$ mixes using GT technology, a simulated steady state thermodynamic cycle has been developed using Aspen Plus.

The cycle consists of a Brayton cycle, followed by a Rankine bottoming cycle, as shown in Figure 21. Although waste heat on site could be used, the Brayton cycle incorporates the use of a recuperator, preheating the air/fuel mix, for a self-sustaining cycle.

The mass flow rate for the inlet is scaled for 10 tonnes of by-product ammonia per day; typical of a medium-sized, modern, 2.7 Mt per annum integrated steelworks site providing for all its coke requirement (i.e. no coke imports). 


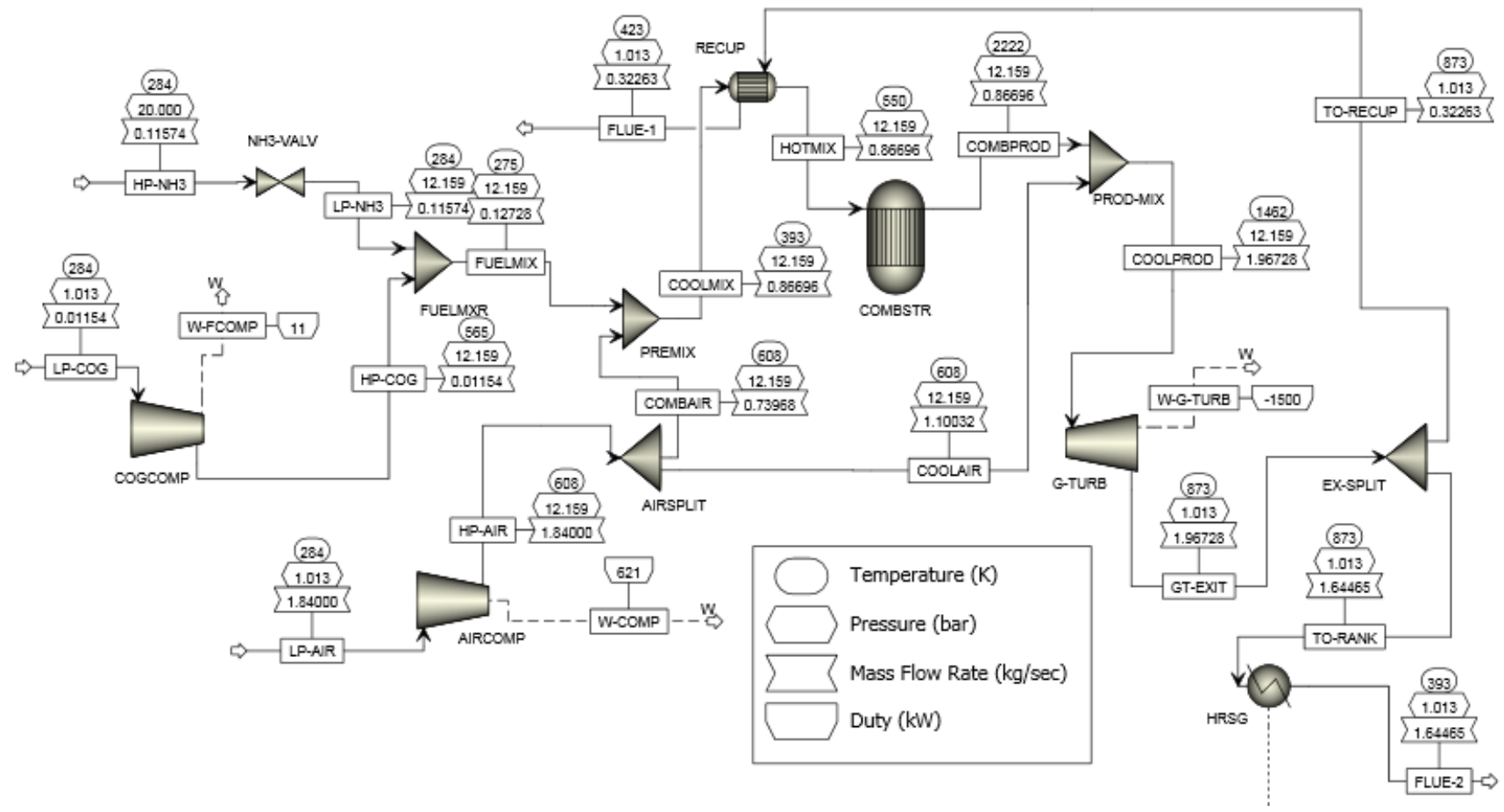

Figure 21. 85\% AMMONIA : 15\% COG BRAYTON CYCLE WITH RECUPERATOR AND HRSG (Ф 1.15) - ASPEN PLUS

Having scaled $\mathrm{NH}_{3}$ mass flows to 10 tonnes per day, the $85 \% \mathrm{AV}$ to $15 \% \mathrm{COG}$ mix (with an $\mathrm{NH}_{3}$ fraction of only $32.2 \%$ of the AV) has a much higher mass flow rate than the equivalent $85 \%$ AA to $15 \%$ COG mix ( $0.43 \mathrm{~kg} / \mathrm{s}$ compared to $0.13 \mathrm{~kg} / \mathrm{s})$. Consequently, the lower heating value available each second is much higher for the AV mix at $4130 \mathrm{~kW}$ compared to $2622 \mathrm{~kW}$ for the AA mix.

These flow rates would not in practice justify a bottoming cycle. However, if green and by-product ammonia become commonplace fuels of the future, scale would naturally increase. By incorporating the Rankine cycle here, comparison with the efficiencies of contemporary combined cycles can be made.

The cycle's ambient temperature has been set to $284 \mathrm{~K}$. The ammonia has a system inlet pressure of $20 \mathrm{bar}(2 \mathrm{MPa})$. For AA, this ensures a liquid state for storage temperature fluctuations. In contrast, $\mathrm{AV}$ at 20 bar is prevented from completely liquefying due to the high partial pressures of the $\mathrm{H}_{2} \mathrm{~S}, \mathrm{HCN}$ and $\mathrm{CO}_{2}$ fractions, presenting a major storage disadvantage.

Air inlet has been modeled for $78 \% \mathrm{~N}_{2}, 21 \% \mathrm{O}_{2}$ and $1 \%$ argon. Species products include all fuel and air components, plus $\mathrm{H}_{2} \mathrm{O}, \mathrm{CO}_{2}, \mathrm{CO}, \mathrm{NO}, \mathrm{NO}_{2}$ and $\mathrm{N}_{2} \mathrm{O}$. The Peng-Robinson fluids package was used in the Brayton cycle (i.e. for air, fuel and exhaust). IAPWS-95 thermodynamic property formulation was used in the water/steam cycle.

\section{Cycle Summary}

A pressure reducing valve for the ammonia, plus compressors for the COG and air feeds, supply a pressure of 12 $\mathrm{atm}(1.2 \mathrm{MPa})$ to the combustion chamber.
The air compressor supplies both the combustion air to the combustion chamber and the cooling air after the combustion chamber, before the turbine. The air splitter 'AIRSPLIT' ensures a specified amount of air for the required $\Phi$ is going to the combustor, with the remainder employed for cooling.

The combustion air, heated by the compressor, is combined with the fuel mix in 'PREMIX'. Before entering the combustor, the premixed air and fuel is preheated to $550 \mathrm{~K}$ through the return of the minimum required percentage of turbine exhaust to the recuperator. The minimum temperature approach between the hot side outlet and cold side inlet of the recuperator is set at $30 \mathrm{~K}$.

The combustion is modeled by a Gibbs reactor, minimizing for free energy. As this cycle is conceptual, no chamber heat losses, combustion efficiency or pressure losses data is available. Therefore, combustion conditions were assumed to be adiabatic, $100 \%$ efficient and with zero pressure losses.

Turbine exhaust flow, not sent to the recuperator, progresses to a heat recovery steam generator (HRSG) the heat energy of which (dotted line) feeds the Rankine cycle. The air supply to the cycle is adjusted, not affecting the specified amount to the combustor, but altering the amount of cooling air The adjustment achieves a turbine exit temperature of $600^{\circ} \mathrm{C}(873 \mathrm{~K})$, similar to exit temperatures of the reference literature $[34,35]$. After the HRSG, the exhaust enters the atmosphere as a vapor at $393 \mathrm{~K}\left(120^{\circ} \mathrm{C}\right)$, above the dew point of water.

The mass flow of water in the simple Rankine cycle is set to automatically adjust its flow to match the heat energy available from the HRSG for raising the maximum amount of steam. A 100 bar (10 MPa) pump, produces saturated steam and 
the final condensation temperature is $20^{\circ} \mathrm{C}(293 \mathrm{~K})$. The steam turbine and condensate pump are operating under ideal reversible conditions and no additional pressure losses are considered. All pressure changers are modeled as single stage.

Although the operating conditions are assumed to be largely ideal, some important and predictable efficiencies were considered [31,32]. For both GT and steam turbines, isentropic and mechanical efficiencies are set to 90 and $99 \%$ respectively. Compressors have $88 \%$ isentropic and $99 \%$ mechanical efficiencies. The water pump has $80 \%$ overall efficiency.

\section{ASPEN PLUS CYCLE RESULTS AND DISCUSSION}

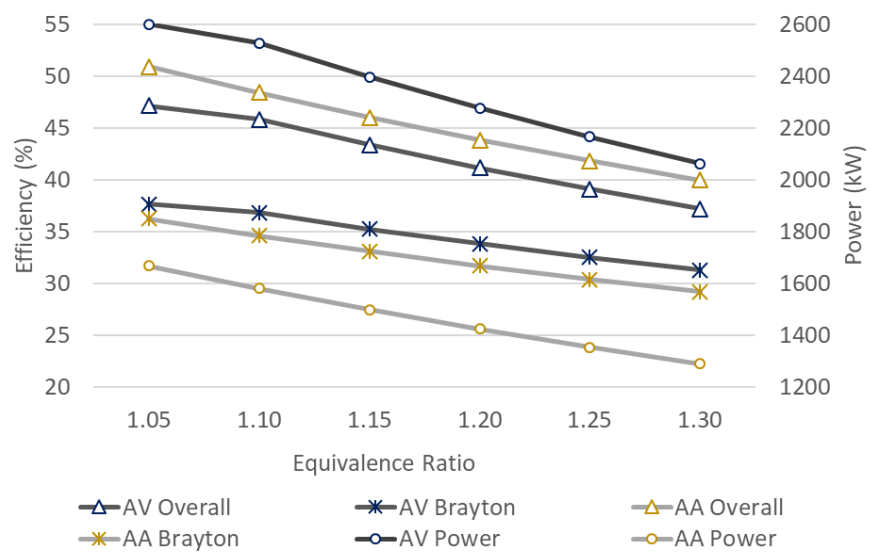

Figure 22. CYCLE EFFICIENCIES AND GT POWER FOR BEST AV AND AA MIXES $\Phi 1.05$ TO 1.3

As Figure 22 indicates, for $\mathrm{AV}$ at $\Phi=1.1$ (within its optimal range of $\Phi 1.05$ to 1.1 ), an overall efficiency of $45.8 \%$ with GT power of approximately $2.53 \mathrm{MW}$ is predicted by the model. Without a steam cycle and with the recuperator (i.e. recuperating Brayton cycle), the efficiency is $36.8 \%$. For AA at $\Phi=1.15$ (within its optimal range of $\Phi 1.1$ to 1.25), overall efficiency is $46.0 \%$, GT power $1.50 \mathrm{MW}$ and Brayton cycle $33.1 \%$. At the $\Phi$ values stated, the recuperator utilizes $47.3 \%$ and $16.4 \%$ of the turbine exhaust in the $\mathrm{AV}$ and AA cycles respectively.

Factoring in heat losses would lower the energy available for power generation, but would also lower the need for cooling air from the compressor.

\section{CONCLUSIONS AND FURTHER WORK}

According to numerical analyses, adding $15 \%$ COG to both the AV and AA gives the optimal balance of reactivity and lower pollutant products.

Optimal $\Phi$ for AV is likely to be lower than for AA, largely due to the higher carbon content, lower reactivity and lower flame speed of the AV mix. Removal of some water content and the carbon containing components $\left(\mathrm{CO}_{2}\right.$ and $\left.\mathrm{HCN}\right)$ with their high partial pressures, would improve reactivity, $\mathrm{CO}$ product and ease of storage However, reducing the water component would most likely increase $\mathrm{NO}_{\mathrm{x}}$, due to higher temperatures. The power potential is greatest when utilizing $\mathrm{AV}$ rather than $\mathrm{AA}$, as it recruits greater amounts of COG and the water fraction improves bulk mass flow.

However, utilizing AA offers the flexibility to incorporate green ammonia and AA recovered from other industrial waste streams (e.g. oil refining and dairy farming) with a resulting increase of scale as the COG represents a minor component of the fuel mix and is under-utilized [22]. AA also offers much improved reactivity and flame speed over AV.

An experimental program will subsequently investigate the chosen mixes at and near their optimal $\Phi$, for performance and products, under the preheated conditions simulated and at elevated pressures. Mixes with 5\% higher and lower COG percentages will also be investigated to verify the numerically predicted trends. Staged combustion will also be undertaken.

\section{ACKNOWLEDGMENTS}

The first author is funded through an EPSRC $\mathrm{PhD}$ Studentship. The project is also supported by FLEXIS (Flexible Integrated Energy Systems) a research operation designed to develop an energy systems research capability in Wales.

$\begin{array}{ll}\text { NOMENCLATURE } \\ 0-\mathrm{D} & \text { Zero Dimensional } \\ 1-\mathrm{D} & \text { One Dimensional } \\ \mathrm{AA} & \text { Anhydrous Ammonia } \\ \mathrm{AV} & \text { Ammonia Vapor } \\ \mathrm{BF}-\mathrm{BOF} & \text { Blast Furnace to Basic Oxygen Furnace } \\ \mathrm{CH}_{4} & \text { Methane } \\ \mathrm{CO} & \text { Carbon Monoxide } \\ \mathrm{CO}_{2} & \text { Carbon Dioxide } \\ \mathrm{COG} & \text { Coke Oven Gas } \\ \mathrm{CRZ} & \text { Central Recirculation Zone } \\ \mathrm{DeNO} & \text { NOx Reduction Process } \\ \mathrm{ER} & \text { Equivalence Ratio } \\ \mathrm{EU} & \text { European Union } \\ \mathrm{GT} & \text { Gas Turbine } \\ \mathrm{H}_{2} & \text { Hydrogen (molecular) } \\ \mathrm{HCN} & \text { Hydrogen Cyanide } \\ \mathrm{HHV} & \text { Higher Heating Value } \\ \mathrm{HRSG} & \text { Heat Recovery Steam Generator } \\ \mathrm{H}_{2} \mathrm{~S} & \text { Hydrogen Sulfide } \\ \mathrm{IEA} & \text { International Energy Agency } \\ \mathrm{Mt} & \text { Million tonnes } \\ \mathrm{NH}_{3} & \text { Ammonia } \\ \mathrm{NO}_{\mathrm{x}} & \text { Nitric Oxide and Nitrogen Dioxide } \\ \mathrm{PFR}_{\mathrm{PSR}} & \text { Plug Flow Reactor } \\ \Phi & \text { Perfectly Stirred Reactor } \\ & \text { Air-Fuel Equivalence Ratio }\end{array}$

\section{REFERENCES}

[1] Worldsteel Association "Energy use in the steel industry", (2018) www.worldsteel.org/publications/factsheets.html

[2] Industrial Efficiency Technology Database "Coke making", http://ietd.iipnetwork.org/content/cokemaking 
[3] Worldsteel Association "Steel and raw materials fact sheet", (2018) https://www.worldsteel.org/steel-bytopic/raw-materials.html

[4] Remus, R., Roudier, S., Aguado-Monsonet, M. A., Delgado Sancho, L. "Best available techniques - iron and steel production", (2013) Industrial Emissions Directive 2010/75/EU. doi:10.2791/97469

[5] Teng, H. "Combustion modifications of batch annealing furnaces and ammonia combustion ovens for NOx abatement in steel plants", Journal of the Air and Waste Management Association, Vol. 46, No. 12, (1996) pp. 1171-1178. doi:10.1080/10473289.1996.10467552

[6] Bermúdez, J. M., Arenillas, A., Luque, R., Menéndez, J. A. "An overview of novel technologies to valorise coke oven gas surplus", Fuel Processing Technology, Vol. 110, (2013) pp. 150-159. doi:10.1016/J.FUPROC.2012.12.007

[7] Djinović, P., Schüth, F. "Energy carriers made from hydrogen", P. and G. Moseley (Ed.), Electrochemical Energy Storage for Renewable Sources and Grid Balancing, (2014) pp. 183-199. doi:10.1016/B978-0444-62616-5.00012-7

[8] Ahlgren, W. L. "The dual-fuel strategy: an energy transition plan", Proceedings of the IEEE, Vol. 100, No. 11, (2012) pp. 3001-3052. doi:10.1109/JPROC.2012.2192469

[9] U.S. Geological Survey Mineral Commodity Summaries - Nitrogen (Fixed) Ammonia (2018) doi:10.3133/70194932

[10] Svoboda, K., Diemer, P. "Catalytic decomposition of ammonia from coke-oven gas", Iron and Steel Engineer, Vol. 67, No. 12, (1990) pp. 42-46

[11] Kohl, A. L., Nielsen, R. Gas Purification, (1997) Gulf Publishing, Houston

[12] Platonov, O. I., Golosman, E. Z., Egorov, M. A., Stepanov, E. N. "The deactivation of the decomposition catalyst of chemical - recovery ammonia", Catalysis in Industry, Vol. 1, No. 1, (2009) pp. 90-93. doi:10.1134/S2070050409010139

[13] Wendt, J. O. L., Sternling, C. V. "Effect of ammonia in gaseous fuels on nitrogen oxide emissions", Journal of the Air Pollution Control Association, Vol. 24, (1974) pp. 1055-1058. doi:10.1080/00022470.1974.10470013

[14] Worldsteel "Steel's Contribution to a low carbon future worldsteel position paper", (2017) https://www.worldsteel.org/en/dam/jcr:66fed386-fd0b485e-aa23-

b8a5e7533435/Position_paper_climate_2017.pdf

[15] International Energy Agency "Iron and Steel - Tracking Clean Energy Progress", (2018) https://www.iea.org/tcep/industry/steel/

[16] Verkamp, F. J., Hardin, M. C., Williams, J. R. "Ammonia combustion properties and performance in gas-turbine burners", Symposium (International) on Combustion, Vol. 11, (1967) pp. 985-992. doi:https://doi.org/10.1016/S0082-0784(67)80225-X
[17] Valera-Medina, A., Morris, S., Runyon, J., Pugh, D. G., Marsh, R., Beasley, P., Hughes, T. "Ammonia, methane and hydrogen for gas turbines", Energy Procedia, Vol. 75, (2015) pp. 118-123. doi:https://doi.org/10.1016/j.egypro.2015.07.205

[18] Okafor, E. C., Naito, Y., Colson, S., Ichikawa, A., Kudo, T., Hayakawa, A., Kobayashi, H. "Experimental and numerical study of the laminar burning velocity of $\mathrm{CH} 4$ NH3-air premixed flames", Combustion and Flame, Vol. 187, (2018) pp. 185-198. doi:10.1016/j.combustflame.2017.09.002

[19] Valera-Medina, A., Pugh, D. G., Marsh, P., Bulat, G., Bowen, P. "Preliminary study on lean premixed combustion of ammonia-hydrogen for swirling gas turbine combustors", International Journal of Hydrogen Energy, Vol. 42, No. 38. (2017) doi:10.1016/j.ijhydene.2017.08.028

[20] Pugh, D., Bowen, P., Valera-Medina, A., Giles, A., Runyon, J., Marsh, R. "Influence of steam addition and elevated ambient conditions on NOx reduction in a staged premixed swirling NH3/H2 flame", (2018) Proceedings of the Combustion Institute. doi:10.1016/j.proci.2018.07.091

[21] Natural Resources Wales. Permit with introductory note No. EPR/BL7108IM (2016)

[22] Pugh, D. Combustion characterisation of compositionally dynamic steelworks gases (2013) Cardiff University PhD Thesis http://orca.cf.ac.uk/58006/

[23] Morley, C. "Gaseq - A chemical equilibrium program for Windows", http://www.gaseq.co.uk/

[24] Valera-Medina, A., Marsh, R., Runyon, J., Pugh, D., Beasley, P., Hughes, T., Bowen, P. "Ammonia-methane combustion in tangential swirl burners for gas turbine power generation", Applied Energy, Vol. 185, (2017) pp. 1362-1371. doi:10.1016/j.apenergy.2016.02.073

[25] European Union "Directive (EU) 2015/ 2193 of the European Parliament and of the Council on the limitation of emissions of certain pollutants into the air from medium combustion plants", Official Journal of the European Union EN, Vol. 451, No. 354, (2014) pp. 13423

[26] Gómez-García, M. A., Pitchon, V., Kiennemann, A. "Pollution by nitrogen oxides: an approach to NOx abatement by using sorbing catalytic materials", Vol. 31, (2005) pp. 445-467. doi:10.1016/j.envint.2004.09.006

[27] Tian, Z., Li, Y., Zhang, L., Glarborg, P., Qi, F. "An experimental and kinetic modeling study of premixed $\mathrm{NH} 3 / \mathrm{CH} 4 / \mathrm{O} 2 / \mathrm{Ar}$ flames at low pressure", Combustion and Flame, Vol. 156, No. 7, (2009) pp. 1413-1426. doi:10.1016/j.combustflame.2009.03.005

[28] Xiao, H., Valera-Medina, A., Marsh, R., Bowen, P. J. "Numerical study assessing various ammonia/methane reaction models for use under gas turbine conditions", Fuel, Vol. 196, (2017) pp. 344-351. doi:https://doi.org/10.1016/j.fuel.2017.01.095 
[29] Xiao, H., Valera-Medina, A., Bowen, P. J. "Modeling combustion of ammonia/hydrogen fuel blends under gas turbine conditions", Energy and Fuels, Vol. 31, (2017) pp. 8631-8642. doi:10.1021/acs.energyfuels.7b00709

[30] Kumar, P., Meyer, T. R. "Experimental and modeling study of chemical-kinetics mechanisms for $\mathrm{H} 2-\mathrm{NH} 3$-air mixtures in laminar premixed jet flames", Fuel, Vol. 108, (2013) pp. 166-176. doi:10.1016/J.FUEL.2012.06.103

[31] Lefebvre, A. H. (Arthur H., Ballal, D. R. Gas Turbine Combustion: Alternative Fuels and Emissions, (2010) Taylor \& Francis

[32] Rutar, T., Malte, P. C. "NOx formation in high-pressure jet-stirred reactors with significance to lean-premixed combustion turbines", Journal of Engineering for Gas Turbines and Power, Vol. 124, No. 4, (2002) pp. 776783. doi:10.1115/1.1492829

[33] Bhargava, A., Colket, M., Sowa, W., Casleton, K., Maloney, D. "An experimental and modeling study of humid air premixed flames", Journal of Engineering for Gas Turbines and Power, Vol. 122, No. 3, (2000) pp. 405. doi:10.1115/1.1286921

[34] Lan, W., Chen, G., Zhu, X., Wang, X., Liu, C., Xu, B. "Biomass gasification-gas turbine combustion for power generation system model based on ASPEN PLUS", Science of The Total Environment, Vols 628-629, (2018) pp. 1278-1286. doi:10.1016/j.scitotenv.2018.02.159

[35] Liu, Z., Karimi, I. A. "Simulating combined cycle gas turbine power plants in Aspen HYSYS", Energy Conversion and Management, Vol. 171, (2018) pp. 1213-1225. doi:10.1016/j.enconman.2018.06.049 